\title{
Teoria e prática da cooperação no viés populista
}

\author{
Theory and practice of cooperation in the populista
}

\begin{abstract}
Resumo
No presente estudo foram analisadas algumas características do cooperativismo, as noções do "novo cooperativismo" ou cooperativismo popular, que (re)surge após a década de 1980 apresentando algumas confusões conceituais da ideia central de cooperativa, e ainda a marginalização midiática e até socioeconômica que as cooperativas populares padecem na contemporaneidade, inclusive dos próprios órgãos de representação dessa iniciativa no país, a Organização das Cooperativas no Brasil - OCB - e suas representações estaduais (OCEe's). Apesar do intenso grau de dificuldade que o cooperativismo popular tem encontrado na atualidade para difundir suas práticas e ideais, esse modelo societário singular tem gerado grande interesse da academia e de determinadas esferas governamentais, como a fomentação e promoção da economia solidária, principalmente após o ano de 2003, no governo Lula, que aos poucos vem municiando os interessados nessa vertente ideológica para um melhor enfrentamento nas barreiras capitalistas e monopolista presentes na atual economia globalizante. Neste sentido, o presente estudo busca através de um estudo de caso específico esboçar algumas realidades que este ramo peculiar do cooperativismo se defronta o mercado, numa ótica bastante diversa em comparação com as grandes cooperativas tradicionais já consolidadas, reconhecidas e legitimadas na sociedade.
\end{abstract}

Palavras-chave: Cooperativismo Popular, Economia Solidária, Economia Globalizante.

\begin{abstract}
In the present study we analyzed some characteristics of cooperatives in general and the notions of the "new cooperative" or cooperative popular that appeared after the 1980s, presenting some conceptual confusions of the central idea of cooperative and marginalization still popular cooperatives that suffer in society in general, including the so-called representative bodies of the initiative throughout the country (OEEC and OCB's), and despite the difficulty that the cooperative has found popular in practice to apply his concepts and ideas he has proven great interest lately the academy and even by certain government departments with the fostering and implementation of real solidarity economy in 2003 under President Lula, who slowly comes municiando interested in this ideological aspect to better cope with the barriers and monopolistic capitalists present in the current globalizing economy
\end{abstract}

Keywords: Cooperativism People's, Solidarity Economy, Economy globalizing.

Recebido: 14/09/2016 Aceito: 16/12/2016

Émerson Dias de Oliveira ${ }^{1}$

${ }^{1}$ Faculdade de Jandaia do Sul - FAFIJAN, Tecnólogo em Gestão de Cooperativas - cooperativismopopular@ hotmail.com

- Rua José Maria de Paula Rodrigues, 2060 - Casa Centro, Jandaia do Sul-PR, CEP: 86.900-000 


\section{Introdução}

$\mathrm{C}$ onsiderando o crescimento diuturno e perverso que a economia apresenta na contemporaneidade, o presente estudo teve como intento inserir uma reflexão enviesada contraditoriamente com a máxima vigente na atual "sociedade do consumo". As análises tiveram como objeto de estudo o funcionamento corriqueiro de uma cooperativa de catadores, a Cooperativa Mista de Trabalho e Produção dos Catadores e Separadores de Materiais Recicláveis de Apucarana-PR - COCAP -, a qual se constitui na coleta, separação e processamento de materiais recicláveis na comunidade local.

O embasamento teórico deu-se com a contextualização da fissura ideológica entre o cooperativismo tradicional, mais conhecido e divulgado no meio social e o cooperativismo popular, o qual é na realidade uma reapresentação dos modelos vigentes ainda no século XVIII. Assim, as argumentações prático-teóricas vão no sentido de evidenciar a importância e utilidade que o cooperativismo popular apresenta, visto que quando bem organizado e apoiado pelos diversos setores da sociedade acaba sendo uma das formas mais acessíveis e democráticas de promover uma perfeita equidade social, fomentando e abrangendo alguns pilares bases da comunidade como: o ambiental; social e econômico.

O desenvolvimento e evolução do cooperativismo popular e da economia solidária no Brasil contribuíram, entre outras questões, para o surgimento de variadas pesquisas nessa área, instituindo uma abordagem científica que evidencia a caracterização distinta dessa unidade econômica. Entretanto, para um melhor entendimento dessa particularidade faz-se necessária uma significativa compreensão a respeito do funcionamento da economia em geral.

Como já apresentado, este estudo pautado na ação de uma cooperativa de caráter popular, a COCAP que iniciou suas atividades no ano de 1999. Esse movimento foi iniciado através da igreja católica local, em menção ao tema da campanha da fraternidade $^{1}$ daquele ano: "Sem Trabalho... Por

\footnotetext{
${ }^{1}$ A Campanha da Fraternidade é uma campanha realizada anualmente pela Igreja Católica Apostólica Romana no Brasil, sempre no período da Quaresma. Seu objetivo é despertar a solidariedade dos seus fiéis e da sociedade em relação a um
}

quê?". Uma iniciativa de vital importância para a sustentabilidade socioeconômica e ambiental local, uma vez que alinhou e interseccionou esses dois elementos de interesse amplificado na sociedade contemporânea.

Esse modelo econômico (cooperativas populares) paralelo e antagônico ao modelo vigente atualmente, tem como caracter central a solidariedade e a autogestão dos empreendimentos, uma arquitetura organizacional em que o trabalho como direito social é efetivamente valorizado e recompensado de maneira justa. Alguns pesquisadores chamam de "Economia Solidária" este estilo singular de fazer as transações trabalhistas e de comércio, a qual "[...] possui uma visão antagônica do sistema capitalista e contrapõe a sua lógica. O seu norte principal é a promoção da cooperação ao invés da competição" (DE OLIVEIRA, 2013, p. 39).

A realidade da economia solidária no Brasil se aproxima profundamente dos contextos políticoeconômicos do país, considerando que somente após a promulgação da dita "constituição cidadã" de 1988 o movimento tomou um rumo mais efetivo no cenário nacional. Após um penoso período de restrição de direitos por parte do Estado (ditadura militar), o país conheceu um estágio extremamente fértil para o crescimento dos Empreendimentos Econômicos Solidários, principalmente após a ascensão de representantes políticos com caracteres políticos de esquerda.

A contextualização panorâmica da economia mundial é bastante importante para situar a ação destes empreendimentos solidários, pois a noção de escala é o elemento principal para dimensionar a posição dos estudos econômicos, identificando devidamente as amplitudes macro e micro de cada contexto pesquisado. Esse debate possibilitou reflexões bastante complexas e sólidas no meio social e acadêmico em relação aos modelos organizativos da economia.

Considerando a realidade brasileira é percebido que sua economia sempre foi carregada de oscilações e instabilidade constante quanto a sua confiabilidade, o que favorece a ampliações dos debates e análises

problema concreto que envolve a sociedade brasileira, buscando caminhos de solução. A cada ano é escolhido um tema, que define a realidade concreta a ser transformada, e um lema, que explicita em que direção se busca a transformação. A campanha é coordenada pela Conferência Nacional dos Bispos do Brasil (CNBB). 
acerca dos seus variados contextos. Após a década de 1990, aconteceram algumas mudanças estruturais na economia nacional, como o advento do plano real, resultando num repentino fortalecimento da moeda $\mathrm{e}$ o consequênte aumento das importações aliado ao enfraquecimento do mercado e da indústria local.

Assim, essa nova realidade na economia contribuiu para o aumento no desemprego, achatamento de salários, informalidade de empresas e funcionários além de outros elementos que culminaram com o surgimento de uma "nova economia" principalmente nas camadas populares da sociedade. Essa "nova economia" chamada por estudiosos do assunto, como o sociólogo Paul Singer de Economia Solidária, tem recebido nos últimos anos do governo federal significativo incentivo e fomento para seu desenvolvimento local.

\section{A Economia Solidária (ES) apresenta-se} atualmente como o sinal mais representativo dos empreendimentos sociais de inclusão socioeconômica em conformidade com os pesquisadores do tema, em que ela usa inúmeras ferramentas para desenvolver suas ideias, como os clubes de trocas, cooperativas populares, associações entre outras iniciativas que facilitam a plena aplicação da economia solidária. Essas ferramentas são mais bem definidas por Mance (2002. p. 87).

As práticas solidárias que materializam a Economia Popular Solidária são constituídas por: autogestão de empresas pelos trabalhadores, agricultura ecológica, consumo solidário, sistemas locais de emprego e comércio, sistemas locais de trocas, Rede Global de Trocas, Redes de Cooperação, organizações comunitárias, Sistemas de Microcrédito e de Crédito Recíproco, Bancos do Povo, Sistemas Locais de Moedas Sociais, movimentos sociais, assentamentos de trabalhadores rurais e sem-terra, autogestão de empresas falidas, prestações de serviços, cooperativas e associações de crédito, consumo, produção etc.

A presente discussão não objeta exaurir as abordagens e apontamentos acerca da Economia Solidária, uma vez que este assunto está em constante debate no meio acadêmico-científico, fazendo-se necessário certo cuidado quando de sua edificação prático-teórica. Os autores da área são praticamente unânimes em afirmar que não existe consenso sobre a definição exata do termo nem das suas características.

A economia solidária recebe distintas e diversas nomenclaturas, mas com conceitos bem parecidos por diversos pesquisadores da temática. Para a pesquisadora Goerck (2010) a Economia Popular Solidária é entendida como o estágio máximo de maturação para uma efetiva aplicação e ocorrência da igualdade social nos empreendimentos comunitários, um cenário onde a vontade local fica expressa no controle e realização efetiva do trabalho.

A maximização dessa discussão decorre de algumas iniciativas e estratégicas organizacionais que ocorreram no meio popular principalmente após a década de 1980, sendo que as duas principais são a Economia Popular, que possuem geralmente enfoques imediatistas visando à geração de trabalho e renda para sua sobrevivência básica e a Economia Solidária, a qual é mais estruturada numa base que visa à manutenção e permanência do trabalho democrático e justo.

A Economia Popular é na realidade uma forma de reproduzir a ideologia capitalista, ocorrendo na maioria das vezes de maneira simplista e superficial, onde geralmente não se faz presente qualquer tipo de técnica de controle para um melhor domínio do empreendimento. Por isso, têm essa nomenclatura de Economia Popular, considerando que acontece dentro da comunidade de maneira informal e onde as referências empreendedoras destas iniciativas geralmente são as empresas capitalistas do seu entorno.

Existe outra iniciativa que também é utilizado no meio social, a Economia Solidária que possui uma visão antagônica do sistema capitalista e contrapõe a sua lógica. O seu norte principal é a promoção da cooperação ao invés da competição, um postulado eternizado com os owenistas ${ }^{2}$, contrário ao contrato perverso e individualista que se faz presente no mercado capitalizado.

Neste sentido, a comparação destes dois tipos econômicos - Economia Popular e Economia Solidária - possibilita a constituição de um novo tipo de empreendimento onde a solidariedade se alia aos aspectos populares da economia. É essa dimensão que

\footnotetext{
${ }^{2}$ Robert Owen introduziu o princípio do cooperativismo, acreditando que se os homens em vez de competir cooperassem uns com os outros alcançariam a tal harmonia de interesses e haveria riqueza para todos (Cole \& Postgate 1971: 216). O modelo owenista serviu de exemplo para a criação de sociedades cooperativas. James Watson, um dos mais distintos líderes dos Radicais da Classe Trabalhadora de Londres (London-WorkingClassRadicals),e William Lovett lideravam a Sociedade Cooperativa de Londres (London Co-operativeSociety), fundada em 1824.
} 
foi trabalho por Goerck (2009), surgindo a noção da Economia Popular Solidária (Figura. 01), onde "encontramos aspectos de solidariedade em empreendimentos organizados pela Economia Popular, para a obtenção de geração de renda por meio do trabalho coletivo entre os sujeitos" (GOERCK, 2010, p. 113).

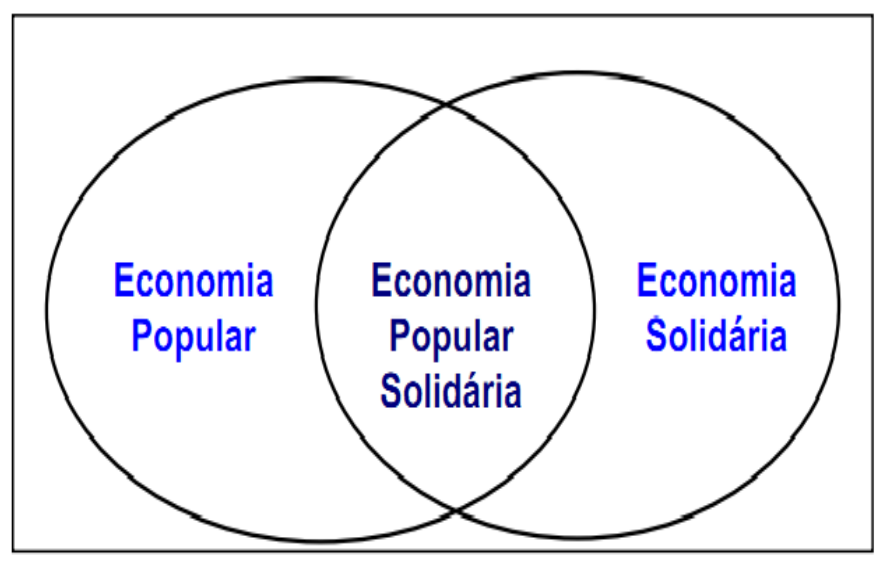

Figura 01: Economia Popular Solidária.

Fonte: GOERCK, 2010.

No contexto da autora, esse novo empreendimento (Economia Popular Solidária) acontece através da aglutinação dos mercados informais (Economia Popular) com as ideias de solidariedade e autoajuda que fomentaram o surgimento do cooperativismo, ou seja, o negócio capitalista praticado na informalidade como exemplos das feiras populares, pequenas iniciativas de trabalhadores em grupos são reordenados com as ideias do mútuo interesse e assim passam a agirem de maneira mais técnica e voltada para o desenvolvimento homogêneo do grupo que fazem parte desta referida iniciativa econômica.

O conceito de Economia Popular Solidária é um estudo em construção e inacabado, nomenclatura utilizada por Razeto (1999) e retomada por Goerck (2010), sendo que no presente estudo será enfocado um debate científico com uma análise focada principalmente nestas características propostas inicialmente por Razeto (1999).

A economia solidária é algo predominante interiorizado nas cooperativas através da distribuição de riquezas e esta centrada no em prol do ser humano e não do capital. Singer (2002) menciona que a economia solidária é outro modo de produção, cujos princípios básicos são a prioridade coletiva ou associada do capital e o direito à liberdade individual.

Enfim, a construção e desenvolvimento deste conceito de acordo com Singer (2003) podem perpassar por diversas acepções, mas, todas giram em torno da ideia de solidariedade em contraste com o individualismo competitivo vigente na economia monopolista do capital.

O Fórum Brasileiro de Economia Solidária define a Economia Solidária (ES) como "fruto da organização de trabalhadores e trabalhadoras na construção de novas práticas econômicas e sociais fundadas em relações de colaboração solidária". Neste contexto, é enfatizada a importância dos valores culturais, que colocam o ser humano como sujeito e finalidade da atividade econômica.

Considerando esses índices sociais oriundos do trabalho solidário, apresenta-se como proposta de trabalho uma investigação acerca do trabalho efetivado pela COCAP, uma instituição que realiza atualmente um trabalho que têm se destacado no município. A Cooperativa, através de determinados programas sociais, passou a empregar várias famílias revertendo e reduzindo algumas desigualdades sociais.

Assim, pretende-se abarcar alguns conceitos sobre a economia solidária, visando construir uma síntese comparativa sobre o modelo organizacional da COCAP em relação as caracteristicas vigentes nos empreendimentos de economia solidária, analisando alguns autores contemporâneos que atuam com esta temática como Paul Singer, Luiz Razzeto, Coraggio, Airton Cançado, Walter Frantz, Nöelle Lechat, Caroline Goerck, entre outros.

O presente estudo se torna viável em razão do histórico que a COCAP possui no município de Apucarana (PR) quando trata-se de trabalho conjunto e solidário de seus componentes, sendo que tal reconhecimento foi notório no início de 2010, quando a instituição foi reconhecida como cooperativa modelo em nível nacional no setor em que atua pelo Banco Nacional de Desenvolvimento Social (BNDS).

Dessa forma, a realização desta pesquisa prioriza e procura uma forma de pulverizar no meio acadêmico a importância social, econômica e ambiental que o trabalho economico-solidário tem para a comunidade em geral, procurando analisar a atuação da COCAP e sua utilidade para o município de Apucarana/PR e região. Considerando que é perceptível ainda a falta de apoio da maioria dos setores locacionais, ou seja, falta uma atuação mais conjunta entre a comunidade e a cooperativa, um reconhecimento profissional, pois lá não existem catadores de lixo, ao contrário, são sócios cooperados que trabalham com materiais 
recicláveis e que apresentam importância essencial para o desenvolvimento social de toda a comunidade.

Logo, fica nítida a importância do trabalho operacionalizado atualmente pela COCAP em Apucarana/PR, pois não enfoca somente a questão ambiental com todas as suas vantagens, mas também exercem influências socioeconômicas como a criação de empregos, distribuição de rendas e a tão mencionada "inclusão social", propagada pelos governantes, ou seja, através de algumas iniciativas cooperativistas é possível algumas conquistas e números até então não contabilizados por vários complexos da administração pública.

Nesse sentido, este estudo buscará servir como ferramenta útil para um melhor entendimento do complexo modelo de organização, trazendo subsídios para fomentar a organização de cooperativas de trabalho em recicláveis como instrumento de inclusão social, a partir da COCAP de Apucarana/PR que têm seu reconhecimento burocrático e no entanto, não possui a mesma situação com os elementos que realmente é de seu interesse, ou seja, a comunidade local de seu meio.

\section{Materiais e Métodos}

O presente estudo usou como procedimento metodológico a realização de pesquisas bibliográficas, onde foram elaboradas diversas análises em materiais publicados, constituídos principalmente de livros, artigos de periódicos e também visitas virtuais em sites de algumas cooperativas e materiais sobre o gênero na internet. Além da observação bibliográfica foi utilizada ainda uma metodologia qualitativa fundamentada na observação livre da atividade e em entrevistas não estruturadas feitas diretamente com os cooperados, priorizando extrair a real situação que os mesmos encontram na cooperativa e qual a percepção e estímulo que estes possuem a respeito da instituição "cooperativa" e da sua ideologia organizacional de atuação no mercado.

Logo, foram realizados trabalhos de campo visando dimensionar a área de influência da atuação da COCAP nos aspectos relacionados ao seu trabalho de coleta, aquisição de cooperados e colaboradores e ainda os mercados em que mantém vínculo de interação nas localidades em seu entorno, utilizando como material de apoio o Plano Diretor Municipal de Apucarana/PR.
O método a ser implantado de coleta de dados embasado na entrevista permite sua obtenção de maneira mais detalhada sobre a complexidade e a abrangência do objeto estudado. Trata-se de um método de coleta de dados que, entre outros objetivos, possibilita captar os motivos conscientes para opiniões, sentimentos, sistemas ou condutas (MARCONI; LAKATOS, 2002).

Neste estudo a entrevista é utilizada para a obtenção de informações a respeito do que realmente se sabe, crêem, esperam, sentem ou desejam, pretendem fazer, fazem ou fizeram e também acerca das suas explicações ou razões a respeito da experiência cooperativista popular.

Considerando-se o seu grau de flexibilidade, as entrevistas são classificadas em estruturadas (ou padronizadas) e não-estruturadas (ou nãopadronizadas). A opção adotada, que melhor servia aos objetivos desta pesquisa, foi o seu molde no formato "não estruturada", que corresponde a um modelo mais flexível, caracterizando-se pela liberdade que o entrevistador tem para desenvolver cada situação em qualquer direção que considere adequada. Geralmente, nesse tipo de questionamento as perguntas são abertas e são respondidas no âmbito de uma conversação. Para GIL (1999), as entrevistas são classificadas em três formatos;

A) Por Pautas: o entrevistador se guia por uma relação de pontos de interesse (pauta), que vai explorando no decorrer da entrevista; tem a liberdade explorar as questões fazendo as perguntas que julgar necessárias, na ordem e profundidade que quiser. É utilizada quando os pesquisados não se sentem à vontade para responder a perguntas formuladas com maior rigidez.

B) Focalizada: há um roteiro de tópicos relativos ao problema que se vai estudar, e o entrevistado fala livremente à medida que se refere a eles. Ao entrevistador cabe conduzir a entrevista não deixando que o entrevistado se desvie do assunto.

C) Não-dirigida: o entrevistado fala livremente a respeito do tema, expressando suas opiniões e sentimentos; o entrevistador tem a função de incentivar a entrevista, levando o informante a falar sobre o assunto, sem, entretanto, lhe fazer perguntas. Esse tipo de entrevista é o menos estruturado possível, sendo utilizado nos estudos exploratórios, que visam abordar realidades pouco conhecidas pelo pesquisador. 
A opção a ser adotada será a modalidade por pautas porque se julga como a mais apropriada para atingir os objetivos de captura das informações necessárias, visto que assim ocorre por parte do entrevistado uma ampla liberdade na construção de suas respostas, priorizando a busca do conceito em si da noção cooperativista e os motivos de estarem atuando na COCAP.

\section{Discussão da Ideia de Cooperação}

A emancipação da ES acontece no fim do século XVIII, com a primeira Revolução Industrial, tomando uma forma mais nítida a partir do século XIX na Inglaterra. Entretanto, somente na segunda metade do século XIX, é que esse tipo de economia realmente configurou-se através do fortalecimento das cooperativas. Para Singer (2002), esses empreendimentos (cooperativas) eram iniciativas provenientes por parte de trabalhadores que visavam recuperar seus empregos e sua autonomia econômica, utilizando suas próprias forças produtivas.

De acordo com Polônio (1999), as primeiras cooperativas constituídas no formato da auto-ajuda tiveram seu início na Europa, sendo que na Inglaterra ainda nos anos de 1844 o primeiro empreendimento cooperativista realmente deu certo e teve sua plena funcionalidade satisfeita, com a fundação da Sociedade dos Probos Pioneiros de Rochedale (Rochdale Society of Equitable Piorneers). A remota cooperativa era composta por 28 tecelões que constituíram a mesma no ramo de consumo, objetivando o enfrentamento da crise industrial da época. Assim, este movimento criou raiz posteriormente na França, Alemanha e mais tarde por toda a Europa.

Conforme Young (2007), a expressão da ES no formato de cooperativas representa um movimento único e uma filosofia de vida, ou seja, é um modelo socioeconômico capaz de unir desenvolvimento econômico e bem-estar social. Os componentes basilares são: participação democrática, solidariedade, independência e autonomia, sendo fundamentado na reunião de pessoas não visando unicamente ao capital, mas às necessidades do grupo e não do lucro, buscando prosperidade conjunta e não individual.

Estas diferenças fazem do cooperativismo a alternativa socioeconômica que leva ao sucesso com equilíbrio e justiça entre os participantes. Associado a valores universais, o cooperativismo se desenvolve independentemente de território, língua, credo ou nacionalidade.

Por volta de 1847 , através do médico francês Jean Maurice Faivre um discípulo dos ideários de Charles Fourier, ocorre no Brasil à instalação da primeira cooperativa entre os colonos europeus nos sertões paranaenses na colônia Tereza Cristina (atual município de Cândido de Abreu-PR) contribuindo para o desenvolvimento desta ideia em todas as demais regiões do país.

Assim, o cooperativismo tomou cada vez mais força e forma no Brasil e teve um enorme crescimento ao longo do séc. XX. Ocorreu ainda a sua legalização e reconhecimento no legislativo com a implantação de diversas leis tratando sobre o assunto.

Atualmente está em vigor a Lei Nacional do Cooperativismo (Lei No 5.764/71) que contribuiu para a incidência de uma profunda melhora em diversos aspectos da ideologia cooperativista no país. Entretanto, esta lei já esta ultrapassada e um novo texto tratando deste assunto está em tramite, principalmente com as lacunas e falhas que o cooperativismo ganhou com a Constituição de 1988, onde ocorreu um impulso na implantação de todo tipo de cooperativas no Brasil, principalmente as cooperativas de trabalho, deixando inclusive margem para mal intencionados atuarem nestas brechas (particularidades) do cooperativismo.

\section{A COCAP e o Cooperativismo}

A fundação da COCAP está extremamente relacionada com a questão da inclusão social, sendo que seu trabalho atual destina um enfoque ao desenvolvimento sustentável e a promoção social do seu quadro de cooperados, visando um trabalho transparente e sem tantas burocracias como ocorre nos meios empresariais tradicionais.

Em entrevista com o gestor da COCAP, Itamar Gomes de Oliveira, a instituição era composta no início por apenas vinte cooperados e possuía pouca infraestrutura. Em meados de 2008 já eram mais de sessenta cooperados, com cerca de quarenta "carrinhos" coletores pela cidade, sendo vinte e duas (22) pessoas responsáveis pela separação dos resíduos na esteira, oito (08) trabalhando no caminhão para coleta em maior quantidade e mais duas (02) cozinheiras, um (01) balanceiro e uma (01) secretária, realizando desta maneira um trabalho de inclusão 
social e atuando de forma direta em prol do meio ambiente.

Atualmente ela conta com 63 cooperados, dentre eles 21 homens e 42 mulheres, com faixa etária que vai dos 16 até 62 anos. Diante dessa realidade, fica evidente que o contexto vivenciado pela cooperativa atualmente os homens contam com maiores chances e oportunidades de empregos em outras áreas, do que as mulheres.

A COCAP trabalha com a coleta e processamento de materiais recicláveis, inserida deste jeito em um dos 13 ramos de trabalho (atuação) do cooperativismo que vigora atualmente no Brasil, sendo que no caso da COCAP ela atua no segmento de Trabalho e Produção, assim entendida pelo órgão de representação do cooperativismo no Brasil (OCB) respectivamente como;

Cooperativa de Trabalho: Cooperativas que se dedicam à organização e administração dos interesses inerentes à atividade profissional dos trabalhadores associados para prestação de serviços não identificados com outros ramos já reconhecidos. As cooperativas de trabalho são constituídas por pessoas ligadas a uma determinada ocupação profissional, com a finalidade de melhorar a remuneração e as condições de trabalho, de forma autônoma. Este é um segmento extremamente abrangente, pois os integrantes de qualquer profissão podem se organizar em cooperativas de trabalho. Cooperativa de Produção: Cooperativas dedicadas à produção de um ou mais tipos de bens e produtos, quando detenham os meios de produção. Para os empregados, cuja cooperativa entra em falência, a cooperativa de produção geralmente é a única alternativa para manter os postos de trabalho. (ORGANIZAÇÃO DAS COOPERATIVAS BRASILEIRAS - OCB 2003, pg. 127).

Estudos da própria Organização das Cooperativas Brasileiras (2005) indicam que os números atuais do cooperativismo no Brasil são de cerca de 7.136 unidades cooperativas. Os membros associados somam quase 6.200.000 (seis milhões e duzentos mil), numa população de uns 120milhões de brasileiros em condições de trabalhar, incluindo tanto jovens como os idosos.

No entanto, esses números são distorcidos em virtudes de muitos empreendimentos cooperativistas não estarem filiados ao órgão de representação do cooperativismo, como o caso da COCAP que não está filiada a OCEPAR ${ }^{3}$. Conforme informações do gestor local, Itamar G. Oliveira, ocorre um desinteresse por parte da organização de representação do cooperativismo no Paraná, além de tal vínculo

\footnotetext{
${ }^{3}$ Organização das Cooperativas Paranaense.
}

representar um aumento nos custos da cooperativa, pois existe uma taxa para a manutenção desta filiação, variante conforme o grau econômico de cada iniciativa cooperativista.

Desta forma, percebe-se que existe na atualidade dos tipos distintos de cooperativismo, o "tradicional" e o "popular", onde a OCB visa valorizar quase que sempre o tradicional em virtude principalmente do enorme retorno financeiro que esses empreendimentos trazem a tona para essa autarquia, deixando à margem do fomento técnico-científico as instituições com viés mais solidário como ocorre com as iniciativas a exemplo da COCAP, que de maneira geral sempre depende do esforço próprio para se impor no mercado de trabalho.

Assim, graças às iniciativas do governo federal, foi criado em 2003 a Secretaria Nacional de Economia Solidária (SENAES) em virtude da valorização dos movimentos sociais organizados em torno da Economia Solidária. Essa secretaria criada no âmbito do Ministério do Trabalho e Emprego ajudou no fomento da geração de trabalho e renda através de uma forma diferenciada de organização do trabalho, a Economia Solidária, sendo que ela ficou sob a responsabilidade técnica do professor Paul Israel Singer.

Conforme já citado, na atualidade a ES já possui seu próprio fórum representativo (Fórum Brasileiro da Economia Solidária) e ainda um projeto de iniciativa popular para criação e regularização da ES no Brasil, ou seja, as perspectivas para o desenvolvimento e valorização de empreendimentos solidários como o caso da COCAP são positivas, que permitirá uma real inclusão destas iniciativas nas faixas de mercado.

A ES apresenta como maneira mais comum e forte de sua representação o "cooperativismo popular", considerando que desde o século XIX a ES já se embasava no "cooperativismo revolucionário" dos socialistas utópicos como forma principal de expressar seus ideários.

Em considerada parcela dos municípios brasileiros existem algumas iniciativas de associação ou cooperativas de coletores de materiais recicláveis. Entretanto, percebe-se que é um pouco dificultoso identificar uma instituição desse cunho que realmente funcione como alternativa econômica solidárias para seus associados, colaboradores ou cooperados.

$\mathrm{Na}$ maioria dos casos, essas iniciativas barram com problemas técnicos, sociais, ideológicos, interesses 
políticos, verbas e ainda, o mais importante, que é o reconhecimento da comunidade local em que essas entidades estão inseridas, que elas são sem dúvidas alguma, o meio mais prático e econômicamente viável para um adequado enfrentamento de diversos problemas sociais.

Essas entidades compostas por coletores de materiais recicláveis possuem uma atuação significativa e meritória, apresentam como foco principal a geração de rendas para seus integrantes. Entretando, os benefícios ambientais são a redução do volume de lixo de difícil degradação, a contribuição para a economia de recursos naturais, prolonga a vida útil dos aterros sanitários, diminui a poluição do solo, da água e do ar e o de evitar o desperdício, contribuindo para uma remodelagem positiva das diversas paisagens ambientais.

De maneira geral, percebe-se que o estágio atual que a economia brasileira passa aliado às pesquisas científicas sobre a ES é de grande importância para o desenvolvimento e profissionalização dos empreendimentos solidários, a exemplo da COCAP, que neste momento pode assumir uma identidade institucional sobre as características e particularidades de sua atuação no mercado, ou seja, este novo estágio da economia ("nova-economia") permite o afloramento e a formalização das iniciativas e empreendimentos solidários que até então mantiveram-se inviáveis economicamente, ideologicamente e politicamente.

\section{O Cooperativismo Popular na COCAP}

As discussões dialogadas nesse estudo evidencia que a realidade cotidiana dos empreendimentos solidários no Brasil atual, é dotada de práticas funcionais bastantes dificultosas, ou seja, carece de um enfoque mais diretivo do poder público e privado para o setor a fim de encaminhar efetivamente os intentos existenciais dessas iniciativas.

Os resultados deste estudo foram obtidos através de questionamentos realizados com 10 (dez) cooperados escolhidos aleatoriamente entre os integrantes da COCAP e uma análise sobre as principais aspirações dos cooperados sobre a atuação da cooperativa.

$\mathrm{O}$ primeiro item analisado foi à pergunta mais óbvia sobre o trabalho dos cooperados da COCAP, um questionamento que não poderia faltar neste trabalho. "Sabe ou entende o que é o
Cooperativismo?", considerando que por estarem trabalhando dentro de uma instituição cooperativista é primordial entender este movimento ideológico.

Assim, através das entrevistas foram sintetizados 03 (três) questionamentos básicos sobre o trabalho investigativo: Entendem parcialmente; Não sabem ou Sabem o significado da instituição (cooperativa) em que atuam, apesar de nem sempre saberem observar corretamente os conceitos aplicados nesta ideologia. A síntese sobre as respostas obtidas aparece na figura 03.

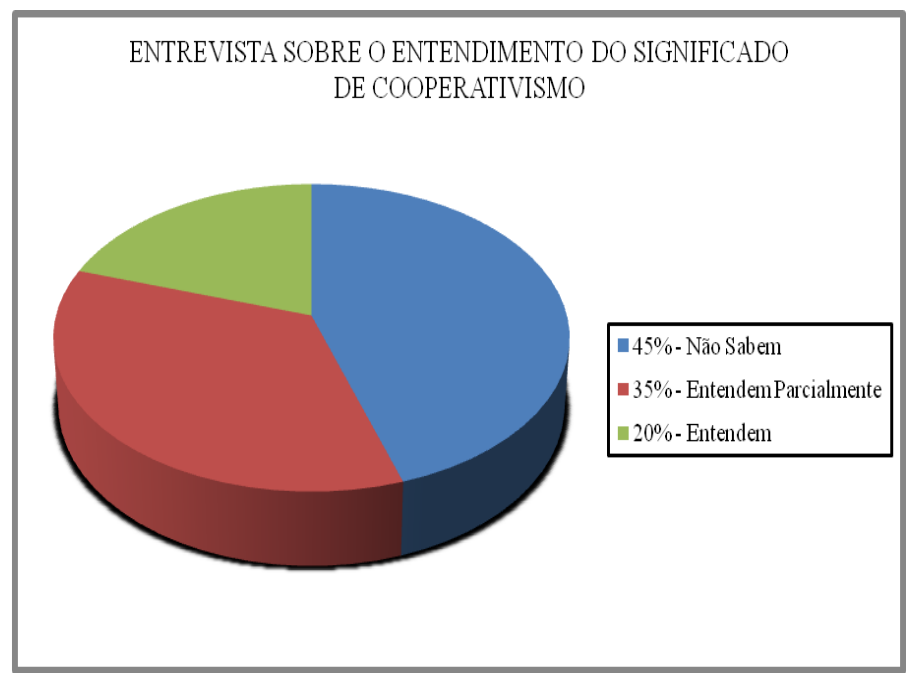

Figura 03: COCAP. "Sabe ou entende o que é o cooperativismo?". Fonte: Pesquisa de Campo

Analisando as respostas obtidas, conclui-se que a minoria dos trabalhadores entende o verdadeiro sentido de cooperativismo e as implicações envoltas neste processo ideológico, ou seja, se faz necessário um fomento técnico-estudantil sobre a gestão, funcionamento e administração da entidade cooperativa, pois não existe na prática uma atuação pró-ativa por parte da maioria do efetivo operacional da COCAP.

Foram elencadas algumas respostas e falas citadas pelos trabalhadores (cooperados) a respeito da noção e entendimento da cooperativa:

"A cooperativa é legal e ajuda todo mundo que trabalha aqui, pois tem comida e um pouco de dinheiro".

"Eu acho que é um monte de gente trabalhando junto e pensa em ganhar dinheiro pra todo mundo".

"Acho que é quando o povo se junta para trabalharem junto".

"Eu to aqui mais não sei o que é ser cooperado, pois nós só trabalhamos juntos". 
Outro questionamento apontado nas entrevistas foi à questão da atuação profissional dos cooperados, ou seja, qual motivo e razão levaram os mesmos a estarem e continuarem trabalhando na COCAP. Assim, no questionário os entrevistados ficaram com a voz ativa e aberta para responderem "Por que estão trabalhando na COCAP?”. Os resultados aparecem na Figura 4.

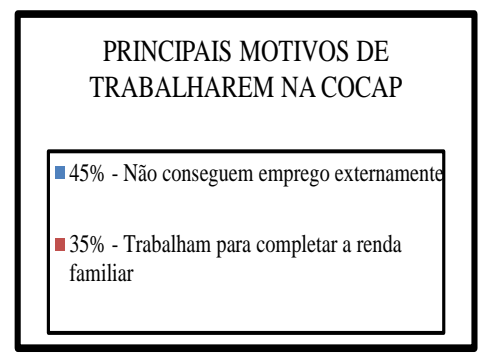

Figura 04: COCAP. "Principais motivos de trabalharem". Fonte: Pesquisa de Campo.

Os cooperados de forma geral, não conseguem se inserir no mercado de trabalho, por não apresentarem algumas qualificações básicas. Do montante de integrantes da COCAP, 37 estão nestas condições, onde alguns possuem idade avançada, a maioria apresenta baixo grau de escolaridade, outros não possuem experiências profissionais as quais são exigidas pelo mercado atualmente.

Outro fator relevante é que a maioria dos trabalhadores precisa ajudar no orçamento mensal familiar. Assim, migram para a cooperativa onde é oportunizado atuarem na coleta e processamento de materiais recicláveis e de certa forma acabam se adaptando e ficam acomodados no serviço.

Com base nas informações relatadas pelos cooperados e nas observações realizadas na COCAP durante a realização deste estudo foi possível à elaboração de um mapa temático dos apontamentos indicados pelos entrevistados (Figura 05) sobre as principais necessidades imediatas da cooperativa, conforme pode ser analisado abaixo.

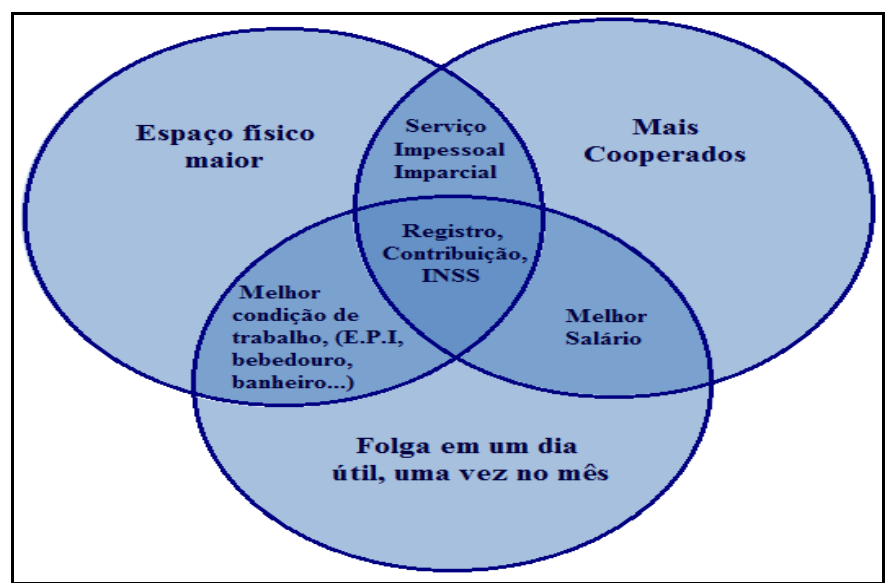

Figura 05: COCAP. Apontamentos dos cooperados sobre as necessidades da cooperativa. Fonte: Pesquisa de Campo

Desta forma, após a realização da pesquisa foram elencadas as principais necessidades que os cooperados da COCAP apontaram como primordial para o dia-a-dia na cooperativa. Iniciando pela tonalidade mais clara até a mais escura aparece nas interseções às prioridades de serviços em déficit na COCAP. A questão do recolhimento previdenciário dos cooperados é a maior preocupação dos mesmos, considerando que a cooperativa ainda apresenta um alto grau de informalidade na relação com seus cooperados e colaboradores.

Assim, vão surgindo outras questões que os cooperados acreditam ser essenciais para o seu próprio desenvolvimento da cooperativa em geral, haja vistas, que tais exigências não são cumpridas ainda de maneira integral pela COCAP, conforme informações dos seus sócios-cooperados.

\section{Considerações Finais}

As reflexões discorridas no decorrer deste estudo comportaram as verificações possíveis no interior da iniciativa de cunho popular e solidário, tendo como objeto as iniciativas impenetradas pelos empreendimentos sociais. Esse tipo peculiar de empreendimento contrário e contraditório aos modelos tradicionais empreendidos no mercado representa uma resposta conjuntural que as iniciativas isoladas no meio social expressam como forma de resistir e lutar contra a lógica do capital.

Essa nova fase e releitura do cooperativismo com o fortalecimento das cooperativas populares em que vigora um modelo de produção e de sociedade que se contrapõe à exploração do modelo capitalista já é realidade no Brasil, principalmente com o surgimento 
das cooperativas de trabalho onde a atuação conjunta dos seus integrantes é valorizada de maneira igualitária.

Nos trabalhos de campos e pesquisas realizadas na COCAP, ficou claro que ainda existe bastante trabalho a ser feito para que a cooperativa atinja a plenitude dos postulados da ES representado pelo cooperativismo popular, haja vista, que a COCAP apresenta quase todos os fatores para dar certo este novo modelo de organização. Entretanto, fazem-se necessárias algumas mudanças essenciais nos processos operacionais e administrativos interno da instituição.

Praticamente inexiste na COCAP um verdadeiro fomento para o seu funcionamento em acordo com as práticas e costumes inerentes aos empreendimentos socioeconômicos, ou seja, é evidente que o postulado "Autogestão" essencial e basilar da ES não se aplica integralmente na COCAP, pois as ações e direcionamento são tomados por intermédio uma minoria do quadro de associados.

Conforme analisado na pesquisa, os cooperados em geral sequer conseguem definir o real conceito de "cooperativismo", trabalham de maneira geral com a noção de uma empresa convencional em que existe um patrão (gestor) responsável pelos direcionamentos da instituição, situação essa que é realidade na COCAP.

Vale citar, no entanto, que não é possível cobrar dos cooperados um feedback de imediato sobre a sua relação e entendimento sobre o cooperativismo em virtude de existir no quadro de cooperado uma maioria sem instrução educacional, realidade essa que deve ser analisada e fomentada nas próximas assembleias da cooperativa.

Como já elencado anteriormente, a ES é recente no meio acadêmico e nas relações econômicas com essa sua nova roupagem. Assim, não seria justo uma cobrança rígida e imediata da COCAP sobre algumas de suas deficiências como modelo de empreendimento econômico-solidário, pois muito já foi feito e continua acontecendo na profissionalização e reconhecimento dos trabalhos realizados pela COCAP.

Desta forma, considerando a significativa liberdade que a academia ainda apresenta na conjuntura nacional para clarificar os distintos contextos socioeconômicos contemporâneos, é o instante dos movimentos e iniciativas de cunho popular e solidário, referenciar-se destes estudos e análises já construídos e em construção para um embasamento mais denso nas realizações de Empreendimentos Sociais. Os meios de superação da exploração capitalistas estão dados: o trabalho abundante, o capital através da autoajuda e as técnicas administrativo-operacionais disponibilizadas nos centros acadêmicos.

Nestes termos, fica evidente que por essas e outras particularidades a COCAP perpassa por um importantíssimo momento de sua existência, a qual deve valer-se dessa ascensão que essa singular noção econômica (economia solidária) apresenta, mesmo com as implicações atuais presente nesta economia monopolista e capitalista que estamos vivenciando.

\section{Referências}

APUCARANA, (PR) Prefeitura Municipal de Apucarana, Plano Diretor de Desenvolvimento para o Município de Apucarana, PR, 1994.

BRASIL. Constituição (1988). Constituição da República Federativa do Brasil: promulgada em 5 de outubro de 1988. Contém as emendas constitucionais posteriores. Brasília, DF: Senado, 1988.

BRASIL. Lei $\mathrm{n}^{\circ} 5.764$ de 16 de dezembro de 1971. Define a Política Nacional de Cooperativismo, institui o regime jurídico das sociedades cooperativas, e dá outras providências. Diário Oficial da União. Brasília, DF, 16 dez. 1971. Disponível em: http://www.planalto.gov.br/ccivil_03/Leis/L5764.h tm>. Acesso em 20 ago. 2015.

DE OLIVEIRA, E. D. Estudo sobre a viabilidade e aplicação do conceito de cooperativas populares: $\mathrm{O}$ caso da COCAP. Dissertação (Mestrado em Geografia), Universidade Estadual de Maringá, Maringá/PR, 2013.

\section{FÓRUM BRASILEIRO DA ECONOMIA SOLIDÁRIA. Disponível em: http://www.fbes.org.br/http://www.ocb.org.br/. Acesso em: 20 out. 2015.}

GIL, A.C. Métodos e técnicas de pesquisa social. 5. ed. São Paulo: Atlas, 1999. 
GOERCK, C. Economia Solidária processo de trabalho. Jundiaí: Ed. Paco, 2010.

MANCE, E. A revolução das redes: a colaboração solidária como alternativa pós-capitalista à globalização. Petrópolis, RJ: Vozes, 2002.

MARCONI, M. A.; LAKATOS, E. M. Técnicas de Pesquisa: planejamento e execução de pesquisas, amostragens e técnicas de pesquisas, elaboração, análise e interpretação de dados. 5. ed. São Paulo: Atlas, 2002.

OCB. Disponível em: http://www.ocb.org.br/ ramos/trabalho_conceito.asp. Acesso em: 11 ago. 2016.

OCEPAR. Disponível em: http://www.ocepar.org.br/ocepar. Acesso em: 13 ago. 2016.

POLONIO, W. A. Manual das sociedades cooperativas. São Paulo: Atlas, $2^{a}$ edição. 1999.

RAZETO, L.. Economia de solidariedade e organização popular. In: GADOTTI, M.;

GUTIÉRREZ, F. (Orgs.). Educação comunitária e economia popular. 2. ed. São Paulo: Cortez, 1999.

SENAES. Disponível em: http://www.ocepar.org.br/ocepar. Acesso em: 11 jul. 2016.

SINGER, P. Introdução a Economia Solidária. São Paulo: Contexto. 2002.

SINGER, P. Globalização e desemprego: diagnóstico e alternativas. São Paulo: Contexto, 1999.

SINGER, P. A formação da classe operária. São Paulo: Atual, 1994.

YOUNG, L. H. B. Sociedades Cooperativas. 7 ed. Curitiba: Juruá, 2007. 
